\title{
Uma chuva constante
}

A Constant Rain

\author{
Helena Motta Monaco' (iD) 0000-0001-8505-8487
}

'Universidade Federal de Santa Catarina, Programa de Pós-Graduação em Antropologia, Florianópolis, SC, Brasil.88040-900-ppgas@contato.ufsc.br

\section{$-$}

DOMÍNGUEZ RUIZ, Ignacio Elpidio.

Bifobia: Etnografía de la bisexualidad en el activismo LGTB.

Barcelona/Madrid: Editorial Egales, 2017 [ebook].

Publicado em outubro de 2017 pelo Editorial Egales, Bifobia: Etnografía de la bisexualidad en el activismo LGTB é, de acordo com o autor, o primeiro livro espanhol sobre bissexualidade (Juan ROURES; Ignacio DOMÍNGUEZ RUIZ, 2018). Nele, Ignacio Elpidio Domínguez Ruiz se dedica ao tema da bifobia no interior do ativismo LGTB, sobretudo em uma associação de Madrid, a Arcópoli, que foi fundada em 2004 e vinculada à Universidad Politécnica de Madrid. Em 2006, se uniu à Federación Estatal de Lesbianas, Gais, Transexuales y Bisexuales (FELGTB), organização que reúne o maior número de associações LGTBs espanholas. Não por acaso a sigla LGTB é utilizada por Domínguez Ruiz nessa ordem, por corresponder ao vocabulário usual nesses contextos de ativismo. O autor ressalta que é devido a esse ativismo que o T aparece antes do B na sigla, ao contrário do que ocorre no mundo anglo-saxão.

No primeiro capítulo, "Metodologia, contexto e compromisso", Domínguez Ruiz apresenta a metodologia utilizada na pesquisa, o contexto do estudo e tece reflexões sobre possibilidades e limites de sua posição enquanto pesquisador e militante filiado à Arcópoli. No segundo, "Bissexualidade e bifobia", explora diferentes definições de "bifobia", provenientes da literatura e de ativistas, e discute as diferenças entre tomá-la como discriminação ou como opressão. No capítulo seguinte, "Estereótipos e resistências", lista estereótipos comumente associados à bissexualidade - por exemplo, estereótipos de promiscuidade e de incapacidade de compromisso -, bem como as formas de resistência adotadas por bissexuais, novamente mobilizando a literatura e relatos de ativistas. O quarto capítulo, "Imagens e conflitos representacionais" trata da dificuldade de representação da bissexualidade através de imagens, as quais se relacionam com diferentes definições e estereótipos de bissexualidade, e quanto a algumas críticas e estratégias utilizadas por ativistas para representar visualmente a bissexualidade. No último capítulo, "Desafios e revoluções futuros" Domínguez Ruiz explora o caráter revolucionário atribuído à bissexualidade na literatura e em discussões sobre bissexualidade.

Ao retomar o título ao livro, o conceito de "bifobia" é central para o debate pretendido. Em entrevista publicada no site Dos Manzanas (ROURES; DOMÍNGUEZ RUIZ, 2018), o autor afirma que foi pensado com o objetivo de causar estranhamento, pois poucas pessoas conhecem a palavra bifobia ou a própria bandeira bissexual (nas cores magenta, lavanda e azul, também representada na capa do livro). Ademais, o objeto da pesquisa é justamente a vivência da bifobia dentro do ativismo LGTB. Entretanto, Domínguez Ruiz não apresenta uma definição única de bifobia, mas uma variedade de definições com base na bibliografia, proveniente de diferentes lugares do 
mundo, sobre bissexualidade, que vai desde as acepções mais simples - como a aversão a pessoas bissexuais - até as mais complexas - que exploram os aspectos preconceituosos e de discriminação voltados à bissexualidade como orientação ou a pessoas bissexuais. O autor destaca, ainda, uma diferença importante entre a homofobia e a bifobia, caracterizando esta última como uma "chuva constante" de bifobia (DOMíNGUEZ RUIZ, 2017), que atinge as pessoas bissexuais. A bifobia se manifestaria em negações da existência ou da validade da bissexualidade, em insultos e violência simbólica. Por sua vez, a homofobia teria maior incidência de violências muito mais visíveis, como insultos e agressões físicas. Para o autor, a prevalência da violência simbólica na bifobia seria um dos motivos para a sua invisibilidade. Em sua concepção, estudar a bifobia no ativismo é importante para entender como funcionam as discriminações particulares em iniciativas que buscam precisamente unir as letras da sigla LGTB, como é o caso da Arcópoli.

Bifobia... é uma etnografia cujo campo de investigação é o Ano da Visibilidade Bissexual na Diversidade ocorrido em 2016. Este foi o último dos anos temáticos - depois dos anos da Visibilidade Lésbica, da Educação Afetivo Sexual, da Transexualidade, do HIV, da Defesa do Matrimônio Igualitário, da Juventude, de Direitos Humanos e de reivindicação por "Leis para a Igualdade Real" - organizados pela FELGTB. Esses anos consistiram em eventos centrados em causas invisibilizadas dentro do ativismo LGTB reformista espanhol. A caracterização como "reformista" definida pelo autor não é empregada em sentido pejorativo, mas faz referência à tendência relativamente recente de ativismo voltado a reformas legislativas como ação política fundamental. O Ano Bissexual teve o objetivo de visibilizar a bissexualidade, combater estereótipos e promover referentes positivos; combater a bifobia e distingui-la da homofobia, bem como promover uma mudança social de forma a romper com o monossexismo através da visibilidade. No contexto pesquisado, o monossexismo é entendido como atitudes que partem da primazia da monossexualidade, ou seja, do desejo por um único sexo/gênero.

Como mencionado anteriormente, Ignacio Elpidio Domínguez Ruiz é associado à Arcópoli e tem um compromisso ativista que norteia sua pesquisa, descrita como uma etnografia militante. Entretanto, cabe ressaltar que o autor não é bissexual. Ele se identifica como sendo um homem homossexual ativista que pesquisa sobre a bifobia no ativismo do qual faz parte. É uma pessoa monossexual investigando os efeitos de práticas que reproduzem a primazia da monossexualidade.

Nesse sentido, Bifobia... combina os posicionamentos existentes na literatura bissexual com as colocações de ativistas bissexuais do coletivo. Apesar disso, as vozes dos ativistas fica relativamente ofuscada pelas reflexões teóricas, em parte pela escolha ética do autor de reproduzir apenas minimamente as falas dos participantes de forma literal. Na medida que são todos ativistas no mesmo grupo, Domínguez Ruiz considera que, se transcritas, as falas seriam facilmente identificáveis por seus companheiros como pertencentes a determinada pessoa. Por esse motivo, optou por parafrasear as falas dos entrevistados, mantendo a versão literal apenas quando considerasse imprescindível. Apesar de eticamente justificada, no entanto, essa escolha deixa a desejar um aprofundamento maior nas falas dos participantes: muitas vezes os posicionamentos ficam vagos e só complementam, confirmam ou fornecem exemplos às reflexões teóricas da bissexualidade apontadas por Domínguez Ruiz a partir da discussão da literatura, trazendo poucas divergências.

Apesar disso, a obra é uma importante contribuição para o estudo das bissexualidades, especialmente considerando que é a primeira a ser escrita na Espanha. Assim como qualquer sexualidade ou identidade, a bissexualidade não representa um grupo homogêneo; ao contrário, as experiências e intersecções são múltiplas. Ao mostrar o caso espanhol, Domínguez Ruiz complementa e complexifica a produção acerca da bissexualidade e contribui para a visibilidade bissexual. No entanto, não explora a bissexualidade em si, como identidade, potência política ou como posição epistemológica, como fazem as chamadas epistemologias bissexuais produzidas principalmente nos Estados Unidos no final da década de 1980 e durante a década de 1990, que colocam a bissexualidade como ponto de partida para essa desconstrução de oposições binárias como heterossexual/homossexual, masculino/feminino (Elizabeth LEWIS, 2012). Ao contrário, o autor concentra-se mais na relação entre a bissexualidade e o movimento LGTB espanhol mostrando a relação conflituosa, frequentemente excludente e violenta quanto à bissexualidade no interior desses grupos. Essa relação conflituosa aparece também em pesquisas sobre bissexualidades no Brasil tal como identificam Camila Dias Cavalcanti (2007) e Elizabeth Lewis (2012) em suas pesquisas no tocante à pouca aceitação de bissexuais e da bissexualidade em movimentos LGBT. Domínguez Ruiz mostra em seu estudo que, no caso espanhol, a bifobia não aparece de forma explícita nos grupos LGTB em decorrência de sua correção política. Entretanto, muitos ativistas declaram sofrer mais bifobia por pessoas gays e lésbicas do que por pessoas heterossexuais. Para essas pessoas, há uma diferença importante entre a bifobia dos heterossexuais - que se resume em desconhecimento e invisibilização da bissexualidade - e a de não-heterossexuais - que envolve a negação e o rechaço. A própria demora em se realizar um ano voltado à bissexualidade pela FELGTB é entendida como ser decorrente da bifobia.

O livro Bifobia... contribui para mostrar que as vivências das bissexualidades são múltiplas, com discussões e divergências até mesmo a respeito da definição de bissexualidade, bem como 
as diferenças entre outras identidades/sexualidades não-monossexuais. Nesse sentido, cabe enfatizar sua importância não apenas para os estudos sobre bissexualidade, mas sobre os movimentos LGBT por mostrar exclusões, conflitos e invisibilidades no interior de grupos de ativismo.

\section{Referências}

DOMÍNGUEZ RUIZ, Ignacio Elpidio Domínguez. Bifobia: Etnografía de la bisexualidad en el activismo LGTB. Barcelona/Madrid: Editorial Egales, 2017 [ebook].

CAVALCANTI, Camila Dias. Visíveis e invisíveis: Práticas e identidade bissexual. 2007. Dissertação (Mestrado em Sociologia) - Programa de Pós-Graduação em Sociologia, Universidade Federal de Pernambuco, Recife, PE, Brasil.

LEWIS, Elizabeth Sara. "Não é uma fase": Construções identitárias em narrativas de ativistas LGBT que se identificam como bissexuais. 2012. Dissertação (Mestrado em Letras) - Programa de PósGraduação em Letras, Pontifícia Universidade Católica do Rio de Janeiro, Rio de Janeiro, RJ, Brasil.

ROURES, Juan; DOMÍNGUEZ RUIZ, Ignacio Elpidio. "Y la bisexualidad, ¿qué?: crítica del ensayo 'Bifobia' y entrevista al autor, Ignacio Elpidio Domínguez Ruíz por Juan Roures”. Dos Manzanas [online], 16/03/2018, às 12:00. Disponível em: https://www.dosmanzanas.com/2018/03/y-labisexualidad-que-critica-del-ensayo-bifobia-y-entrevista-a-su-autor-ignacio-elpidio-dominguezruiz.html. Acesso em: 10/01/2019.

Helena Motta Monaco (helenamonaco@gmail.com) é bacharela e licenciada em Ciências Sociais pela Universidade Federal de Santa Catarina. Atualmente, cursa mestrado em Antropologia Social na mesma universidade. É integrante do Núcleo de Antropologia do Contemporâneo (Transes/UFSC) e desenvolve pesquisa sobre bissexualidade, monodissidência e ativismo bissexual.

\section{COMO CITAR ESSE ARTIGO DE ACORDO COM AS NORMAS DA REVISTA}

MONACO, Helena Motta. "Uma chuva constante". Revista Estudos Feministas, Florianópolis, v. 28, n. 2, e63438, 2020.

\section{CONTRIBUIÇÃO DE AUTORIA}

Não se aplica.

\section{FINANCIAMENTO}

O presente trabalho foi realizado com apoio da Coordenação de Aperfeiçoamento de Pessoal de Nível Superior - Brasil (CAPES) - Código de Financiamento 001.

\section{CONSENTIMENTO DE USO DE IMAGEM}

Não se aplica.

APROVAÇÃO DE COMITÊ DE ÉTICA EM PESQUISA

Não se aplica.

\section{CONFLITO DE INTERESSES}

Não se aplica.

\section{LICENÇA DE USO}

Este artigo está licenciado sob a Licença Creative Commons CC-BY International. Com essa licença você pode compartilhar, adaptar, criar para qualquer fim, desde que atribua a autoria da obra.

\section{HISTÓRICO}

